\title{
Identification and Mode of Action of Antibacterial Components from Melastoma malabathricum Linn Leaves
}

\author{
${ }^{1}$ Mourouge Saadi Alwash, ${ }^{1}$ Nazlina Ibrahim and ${ }^{2}$ Wan Yaacob Ahmad \\ ${ }^{1}$ School of Biosciences and Biotechnology, \\ ${ }^{2}$ School of Chemical Sciences and Food Technology, \\ Faculty of Science and Technology, Universiti Kebangsaan Malaysia, 43600, Bangi, Selangor, Malaysia
}

Received 2013-05-02, Revised 2013-06-17; Accepted 2013-06-18

\begin{abstract}
The present study aimed to assess the antibacterial activity of the methanol extract of Melastoma Malabathricum Leaves (MMML), active fraction of M. malabathricum leaves (ML5) and isolated kaempferol-3-O-(2",6"-di-O-p-trans-coumaroyl)- $\beta$-glucopyranoside (Kf) and to describe the preliminary mode of action against Gram-positive and Gram-negative bacteria. The MMML extract was fractionated by Vacuum Liquid Chromatography (VLC) to afford M. malabathricum leaves fractions (ML1-ML6) of increasing polarities. Bioassay-guided fractionation (direct-TLC bioautography) revealed that fraction of $M$. malabathricum Leaves (ML5) had the highest antibacterial activity. Therefore, the ML5 was further subjected to Column Chromatography (CC) to afford Kaempferol-3-O-(2",6"-di-O-p-trans-coumaroyl)- $\beta$ glucopyranoside (Kf). The compound structure was elucidated using data obtained from ${ }^{1} \mathrm{H}$ NMR and ${ }^{13} \mathrm{C}$ NMR spectra. Antibacterial activity of MMML, ML5 and bioactive constituents Kf against Staphylococcus aureus reference strain, Methicillin-Resistant S. Aureus reference strain (MRSA), 11 clinical MRSA isolates, 3 clinical Pseudomonas aeruginosa isolates and $P$. aeruginosa reference strain was evaluated through disk diffusion method and Minimum Inhibitory Concentration (MIC). The time kill assay and field emission scanning electron microscopy was used to determine the preliminary mode of action. The data obtained from disk diffusion method and MIC showed that the MMML, ML5 and Kf showed antibacterial activity against all test bacteria with various values. Generally, the ML5 and Kf exhibited the highest antibacterial activity with the largest zones of inhibition and lowest MIC values against $S$. aureus and all tested MRSA. The MMML exerted the strongest killing effect against all tested bacteria while the overall performance of ML5 and Kf were significantly more effective against $S$. aureus and MRSA than $P$. aeruginosa. Field emission scanning electron microscopy revealed irregular bacterial surface indicating that the MMML, ML5 and Kf disrupted the integrity of membrane. The results obtained showed that MMML, ML5 and Kf have potential alternative to antibiotics.
\end{abstract}

Keywords: Melastoma Malabathricum Linn Leaves, Flavonoids, Antibacterial and Mode of Action

\section{INTRODUCTION}

Infectious diseases caused by pathogenic microorganisms such as bacteria, viruses, parasites or fungi affect millions of people worldwide. Discovery of antibiotics was an essential part in combating bacterial infections especially when the diseases remained as the major cause of mortality (Chanda and Rakholiya, 2011). The development of resistance to available antibiotics is a worldwide concern. Antimicrobial Resistance (AMR) is resistance of a microorganism to an antimicrobial medicine to which it was previously susceptible.

Corresponding Author: Nazlina Ibrahim, School of Biosciences and Biotechnology, Faculty of Science and Technology, Universiti Kebangsaan Malaysia, 43600, Bangi, Selangor, Malaysia 
Resistant microorganisms are able to withstand attack by antimicrobial medicines. Though, standard treatments become ineffective and infections persist and may spread to others. AMR is a consequence of the use, particularly the misuse of antimicrobial medicines and develops when a microorganism mutates or acquires a resistance gene. Globally, a high percentage of hospital-acquired infections are caused by highly resistant bacteria such as Methicillin-Resistant Staphylococcus Aureus (MRSA) and Pseudomonas aeruginosa (WHO, 2012). MRSA is a serious current health care concern with both community-associated MRSA and health care-associated MRSA are growing threats to the immune compromised patients (Broekema et al., 2009). Furthermore, it is a major pathogen that causes a wide variety of diseases from common and mostly uncomplicated to severe invasive infections such as intravenous catheter associated infections, ventilator associated pneumonias and surgical wound infections (Uhlemann et al., 2013). On the other hand, $P$.aeruginosais one of the major causes of nosocomial infections that is highly related to opportunistic infections among hospitalized patients. It causes urinary tract infections, respiratory system infections, soft tissue infections, dermatitis, bacteremia, bone and joint infections, gastrointestinal infections and a variety of systemic infections, particularly in patients with severe burns and in cancer and AIDS patients who are immune suppressed. With the huge threat posed by these bacterial pathogens and the need to develop safe, more dependable than costly drugs that have no adverse side effect and potent alternatives to existing drugs. However, plant extracts and bioactive constituents isolated from ethnomedicinal plants are considered prolific resources for novel antibacterial substances with various structures and new mechanisms of action (Rios and Recio, 2005).

An increasing interest in the search for chemotherapeutics agents from natural sources including ethno medicinal plants used in traditional medicine (Sharma et al., 2010). In many areas, particularly in the tropical countries, traditional medicinal plants remain one of the main sources in prevention and treatment of varying ailments through self-medication (Mahomoodally et al., 2012). Melastoma malabathricum Linn. (Melastomataceae) is one of the most important herbs or shrubs found in Malaysia and known to Malays as "senduduk". The plant has been used in traditional Malay medicine for alleviating diarrhea, leucorrhoea, puerperal infection, dysentery; wound healing, post-partum treatment and haemorrhoids (Sirat et al., 2010; Zakaria et al., 2011).
Several activities have been reported to $M$. malabathricum leaves including antiviral activity (Nazlina et al., 2008), antibacterial activity (Sunilson et al., 2008; Zulaikah et al., 2008; Choudhury et al., 2011), antioxidant activity (Sirat et al., 2010) and antinociceptive, anti-inflammatory and antipyretic activity (Zakaria et al., 2006).

In spite of different medicinal uses and various types of bioactive constituents isolated and identified from $M$. malabathricum, their therapeutics efficacy and mode of action are still unknown (Mohd. Joffry et al., 2012). Therefore, the scope of the present study is (1) to evaluate the antibacterial activity of the methanol extract of M. Malabathricum Leaves (MMML), active fraction of $M$. malabathricum Leaves (ML5) and isolated Kaempferol-3-O-(2",6"-di-O-p-trans-coumaroyl)- $\beta$ -

glucopyranoside (Kf) against $S$. aureus, Methicillinresistant $S$. aureus and $P$. aeruginosa; (2) to describe the preliminary mode of action using time kill assay and field emission scanning electron microscopy.

\section{MATERIALS AND METHODS}

\subsection{Plant Extract and Isolation of Compound}

M. malabathricum Linn leaves was purchased from Ethno Herbs Resources Sdn. Bhd (Malaysia) and identified by a botanist with the specimen voucher NI01 deposited in the Herbarium, Faculty of Science and Technology, Universiti Kebangsaan Malaysia. In preliminary extraction, $50 \mathrm{~g}$ of powdered plant leaves from M. malabathricum was treated with $n$-hexane to remove fats, waxes and chlorophylls. This is followed by extraction with methanol $(\mathrm{MeOH})$ according to Green (2004) using solvent to sample dry weight ratio of 10:1 $(\mathrm{v} / \mathrm{w})$. The powdered plant leaves were stirred vigorously in $\mathrm{MeOH}$ at ambient temperature for $72 \mathrm{~h}$. After $24 \mathrm{~h}$, the liquid was removed and filtered through Whatman No.1 filter paper. $\mathrm{MeOH}$ was again added to the powdered leaves. The method was repeated three times. The filtered extract was dried by rotary evaporator at $40^{\circ} \mathrm{C}$ to yield the methanol extract of M. malabathricum Leaves (MMML). The MMML was fractionated by Vacuum Liquid Chromatography (VLC) on silica gel 60 (Merck, Germany; Art no.1.07747.1000) and eluted with gradient solvent system of $n$-hexane: Ethyl acetate (EtOAC) $(9: 1,7: 3,5: 5,3: 7$ and 1:9) and EtOAC: $\mathrm{MeOH}$ $(9: 1,8: 2,7: 3,6: 4,5: 5,4: 6,3: 7,2: 8$ and 1:9) and finally $\mathrm{MeOH}$. Solvents used were analytical grade (Merck, Germany). Fractions were combined based on similar profile using Thin Layer Chromatography (TLC Kieselgel 60PF254; Merck, Germany; Art 
no.1.05554.0001) plates to afford six fractions of $M$. malabathricum Leaves (ML1-ML6) according to difference in polarity and type of constituents extracted. Direct TLC-bioautography was performed to determine specific fraction showing the highest numbers of antibacterial components with sufficient amount (Sgariglia et al., 2011). The fraction ML5 is then further fractionated by pre-adsorption on silica gel and further subjected to Column Chromatography (CC) on silica gel 60 (Merck, Germany; Art no. 1.09385.1000) and eluted with the gradient solvent system of chloroform: $\mathrm{MeOH}$ to yield bioactive flavonoids. The structure of the active compound Kaempferol-3-O-(2",6"-di-O-p-transcoumaroyl)- $\beta$-glucopyranoside (Kf) was elucidated using data obtained from ${ }^{1} \mathrm{H}$ NMR and ${ }^{13} \mathrm{C}$ NMR spectra.

\subsection{Determination of Antibacterial Activity}

\subsubsection{Bacterial strains and Growth Condition}

Staphylococcus aureus reference strain ATCC 11632, Methicillin-Resistant $S$. Aureus reference strain ATCC 43300 (MRSA), 11 clinical MRSA isolates, Pseudomonas aeruginosa reference strain ATCC 10145 and 3 clinical $P$. aeruginosa isolates were kindly provided by the Microbiology Laboratory, School of Biosciences and Biotechnology, Faculty of Science and Technology, Universiti Kebangsaan Malaysia. The bacteria cultures were maintained in Brain Heart Infusion Broth (BHIB; Oxoid, UK). Bacteria were cultured at $37^{\circ} \mathrm{C}$ for $24 \mathrm{~h}$ and then sub-cultured on BHI agar (Oxoid, UK) at $37^{\circ} \mathrm{C}$ for 24 h. For each experiment, bacteria were re-suspended in $0.85 \%$ saline to obtain the required densities equivalent to the McFarland 0.5 turbidity standard.

\subsection{Disk Diffusion Method}

Antibacterial activity of the MMML, ML5 fraction and bioactive compound (Kf) was determined by disk diffusion method according to CLSI (2006). Briefly, 100, 40 and $20 \mathrm{mg} \mathrm{mL}^{-1}$ of the MMML, ML5 and Kf were dissolved in 5\% Dimethylsulfoxide (DMSO, Merck, Germany). The surface of the Mueller-Hinton Agar (MHA; Oxoid, UK) was inoculated using a $100 \mu \mathrm{L}$ of 0.5 McFarland standardized inoculum suspension of bacteria and allowed to dry. Sterile filter paper disks (6 $\mathrm{mm})$ were impregnated with $10 \mu \mathrm{L}$ of each concentration, air dried, placed onto MHA and incubated at $37^{\circ} \mathrm{C}$ for $24 \mathrm{~h}$. Vancomycin $\left(5 \mu \mathrm{g} \operatorname{disk}^{-1}\right)$ and ciprofloxacin $\left(5 \mu \mathrm{g} \mathrm{disk}{ }^{-1}\right)$ were used as positive control or reference antibiotics whilst 5\% DMSO serves as a negative control. The tests were performed in triplicate and the antibacterial activity was expressed as the mean of the inhibition zones diameter in millimeters $(\mathrm{mm})$.

\subsection{Minimum Inhibitory Concentration (MIC) Determination}

Minimum Inhibitory Concentrations (MICs) were determined according to NCCLS (2000). Various concentrations of the MMML, ML5 fraction and bioactive compound (Kf) were prepared in MuellerHinton broth (MHB; Oxoid, UK) to a final volume of $100 \mu \mathrm{L}$ in round bottom microplate with 96-well. Bacterial suspension adjusted to $0.5 \mathrm{McFarland}$ standards was added to test solutions or antibiotic controls to a final volume of $200 \mu \mathrm{L}$ well ${ }^{-1}$. The negative control wells received only $200 \mu \mathrm{L}$ of MHB. All tests were performed in triplicate. The MIC was recorded as the lowest concentration that produced a complete suppression of visible growth after $24 \mathrm{~h}$ incubation at $37^{\circ} \mathrm{C}$.

\subsection{Minimum Bactericidal Concentration (MBC) Determination}

To determine minimum bactericidal concentrations (MBCs), an aliquot of $5 \mu \mathrm{l}$ was withdrawn from wells with no bacterial growth and plated onto Nutrient agar (NA; Oxoid, UK) then incubated overnight at $37^{\circ} \mathrm{C}$. The lowest concentration which showed no growth on the agar was defined as the MBC.

\subsection{Time-Kill Studies}

The effects of the MMML, ML5 fraction and Kf on the viability of cells were monitored by Microdilution method according to NCCLS (1999). Overnight culture was inoculated into Nutrient broth (NB, Oxoid, UK) and incubated at $37^{\circ} \mathrm{C}$ with agitation at $151 \mathrm{rpm}$ (Blue Pard, China). To each round bottom well (96-well), $100 \mu \mathrm{L}$ of bacterial suspension adjusted to approximately $4 \times 10^{5}$ colony forming unit (CFU)/ml was added to $\mathrm{MHB}$ containing the MMML, ML5 fraction and Kf at different concentrations of $1 \times, 2 \times$ and $4 \times$ MIC to a final volume of $200 \mu \mathrm{L}$ well $^{-1}$. Aliquots were removed at $0,4,8,12$ and $24 \mathrm{~h}$. post inoculation. Samples were serially diluted $\left(10^{-1}-10^{-4}\right)$ in $0.85 \%$ saline. Thereafter, $10 \mu \mathrm{L}$ of each dilution was spread aseptically onto nutrient agar and incubated at $37^{\circ} \mathrm{C}$ for $24 \mathrm{~h}$. Colonies were counted after $24 \mathrm{~h}$ of incubation. All experiment was carried out in triplicate. Bactericidal activity was defined as a $\geq 3$ $\log _{10}$ reduction in the number of survivors at each time point compared with original inoculum $(99.9 \%)$ at zero time point after $24 \mathrm{~h}$ incubation. Bacteriostatic activity was defined as maintenance of or a $<3 \log _{10}$ decrease in the total colony forming unit $\mathrm{CFU} / \mathrm{ml}$ from initial inoculums (99.9\%). Killing curves were plotted as mean colony counts against time. 


\subsection{Field Emission Scanning Electron Microscopy (FESEM)}

Field emission scanning electron microscope (FESEM) was employed to observe morphological changes in test organisms caused by the MMML, ML5 fraction and bioactive constituent $(\mathrm{Kf})$ following the method modified from Sharifa et al. (2007). Inocula of $S$. aureus, MRSA and $P$. aeruginosa were prepared as described previously in time-kill assay. Bacterial growth was incubated with and without MMML, ML5 fraction and bioactive constituent at $37^{\circ} \mathrm{C}$ on shaker-incubator. Briefly, harvested cells were centrifuged at 3,000 rpm (Beckman Coulter Inc, Germany) for $15 \mathrm{~min}$ and then fixed in $2 \%$ glutaraldehyde in $0.1 \mathrm{M}$ phosphate buffer overnight at $4^{\circ} \mathrm{C}$. Cells were collected by centrifugation, washed thrice with Phosphate Buffer Solution (PBS) $\mathrm{pH}$ 7.4. Cells were serially dehydrated with 30,50 and $70 \%$ ethanol respectively for $5 \mathrm{~min}$, followed by centrifugation for $10 \mathrm{~min}$ at $3000 \mathrm{rpm}$ after each dehydration process. An aliquot of $20 \mu \mathrm{L}$ of bacterial pellets were applied on Poly-L-Lysine slide (Poly-LLysine $0.1 \%$ in water; Sigma, France), subjected to gold coating and observed under FESEM (Zeiss, Supra $^{\mathrm{TM}} 55 \mathrm{VP}$, Germany).

\section{RESULTS}

\subsection{Isolation and Evaluation of Active Constituent with Antibacterial Activity}

The chromatographic separation of MMML by VLC afforded six M. malabathricum Leaves fractions (ML1ML6). Bioassay-guided fractionation, direct TLCbioautography revealed that the ML5 fraction showed the highest numbers of antibacterial components with sufficient amount (2.5 g per $1 \mathrm{~kg}$ of MMML). The bioactive constituents responsible for antibacterial activity against $S$. aureus and MRSA were detected. This is followed by purification of ML5 by Column Chromatography (CC) which resulted in the isolation of an effective compound. The structure of the compound was elucidated using data obtained from ${ }^{1} \mathrm{H}$ and ${ }^{13} \mathrm{CNMR}$ spectra and identified as Kaempferol-3-O-(2",6"-di-O-ptrans-coumaroyl)- $\beta$-glucopyranoside, $\mathrm{Kf}$ (Fig. 1).

\subsection{Evaluation of Antibacterial Activity}

The MMML, ML5 and Kf from M. malabathricum were evaluated for their antibacterial activity against selected bacteria. The zones of inhibition, Minimum Inhibitory Concentration (MIC) values and Minimum
Bactericidal Concentration (MBC) values of the MMML, ML5 and Kf for selected bacteria are shown in the Table 1. The MMML displayed potent antibacterial activity with larger zones of inhibition diameter equal to $19 \pm 0 \mathrm{~mm}$ for $S$. aureus between $18 \pm 0$ to $20.33 \pm 0.58$ $\mathrm{mm}$ for MRSA and from $15.33 \pm 0.58$ to $20 \pm 0 \mathrm{~mm}$ for $P$. aeruginosa at concentration $1000 \mu \mathrm{g} \operatorname{disk}^{-1}$ (Fig. 2). The zones of inhibition of the ML5 were $15.67 \pm 0.58 \mathrm{~mm}$ for $S$. aureus, between $15.33 \pm 0.58$ to $17 \pm 0 \mathrm{~mm}$ for tested MRSA and from $13 \pm 0$ to $15 \pm 0$ $\mathrm{mm}$ for all tested $P$. aeruginosa at $400 \mu \mathrm{g} \operatorname{disk}^{-1}$. The antibacterial activity of $\mathrm{Kf}$ is presented in Table $\mathbf{1}$. Generally, Kf showed different pattern of antibacterial activity in Gram-positive and Gram-negative bacteria. Inhibition towards $P$. aeruginosa was less than inhibition towards $S$. aureus and MRSA.

In order to obtain more quantitative and concise results, the disk diffusion method was compared with $\mathrm{MIC}$ and $\mathrm{MBC}$ values. Higher MIC and MBC values of MMML against all tested bacteria were observed compared to the ML5 values (Table 1). In general, the MMML exhibited antibacterial activity with the MIC values between $0.78 \pm 0$ to $3.13 \pm 0 \mathrm{mg} \mathrm{mL}^{-1}$ against all tested pathogenic bacteria whereas the MIC values of ML5 against $S$. aureus and MRSA were found to be relatively lower than $P$. aeruginosa and ranged from $0.125 \pm 0$ to $0.25 \pm 0 \mathrm{mg} \mathrm{mL}^{-1}$ (Table 1). The data obtained from MIC values showed that $\mathrm{Kf}$ at concentration ranging from $0.125 \pm 0$ to $0.25 \pm 0 \mathrm{mg}$ $\mathrm{mL}^{-1}$ inhibit the growth of $S$. aureus and MRSA while the MIC values varied between $0.5 \pm 0$ and $1 \pm 0 \mathrm{mg}$ $\mathrm{mL}^{-1}$ against $P$. aeruginosa. Kf showed almost the same MIC values with several MRSA strains and $S$. aureus strain (Table 1).

\subsection{Time kill assays}

The time-kill studies were used to assess the time needed by MMML, ML5 and Kf to act on bacterial cells viability of $S$. aureus, MRSA and $P$. aeruginosa. The time kill curves for $S$. aureus, MRSA and $P$. aeruginosa of MMML are shown in Fig. 3A-C. As shown in Fig. 3, treatment of $S$. aureus with MMML at concentrations $1 \times, 2 \times$ and $4 \times$ MIC was successful in killing bacterial cells within $8 \mathrm{~h}$. However, the treatment of MRSA with MMML at concentrations $2 \times$ and $4 \times$ MIC showed lethal effect after $8 \mathrm{~h}$. Complete lethality occurred at $1 \times, 2 \times$ and $4 \times$ MIC within 12,12 and $8 \mathrm{~h}$. Respectively after treating $P$. aeruginosa with MMML. 
Mourouge Saadi Alwash et al. / American Journal of Infectious Diseases 9 (2): 46-58, 2013

Table 1. Antibacterial activity of the methanol extract of Melastoma malabathricum Linn leaves (MMML), M. malabathricum leaves fraction (ML5) and Kaempferol-3-O-(2",6"-di-O-trans-pcoumaroyl)- $\beta$-D-glucopyranoside (Kf) against tested bacteria species (reference strains and clinical isolates), determined by disk diffusion method and minimum inhibitory concentration. The values are the means of replicates \pm standard deviation.

\begin{tabular}{|c|c|c|c|c|c|c|c|c|c|c|c|c|}
\hline \multirow[b]{5}{*}{ Test bacteria } & \multicolumn{12}{|c|}{ Plant extract/ML5 fraction/Bioactive compound Kf } \\
\hline & \multicolumn{4}{|l|}{ MMML } & \multicolumn{4}{|l|}{ ML5 } & \multicolumn{4}{|l|}{$\mathrm{Kf}$} \\
\hline & \multicolumn{12}{|c|}{ Susceptibility of Bacteria $(\mathrm{mg} / \mathrm{ml})$} \\
\hline & \multicolumn{4}{|c|}{ Zone of inhibition (mm) } & \multicolumn{4}{|c|}{ Zone of inhibition (mm) } & \multicolumn{4}{|c|}{ Zone of inhibition (mm) } \\
\hline & $\begin{array}{l}500 \\
\mu \mathrm{g} / \text { disk }\end{array}$ & $\begin{array}{l}1000 \\
\mu \mathrm{g} / \text { disk }\end{array}$ & $\begin{array}{l}\mathrm{MIC} \\
\mathrm{mg} / \mathrm{ml}\end{array}$ & $\begin{array}{l}\mathrm{MBC} \\
\mathrm{mg} / \mathrm{ml}\end{array}$ & $\begin{array}{l}200 \\
\mu \mathrm{g} / \text { disk }\end{array}$ & $\begin{array}{l}400 \\
\mu \mathrm{g} / \text { disk }\end{array}$ & $\begin{array}{l}\mathrm{MIC} \\
\mathrm{mg} / \mathrm{ml}\end{array}$ & $\begin{array}{l}\mathrm{MBC} \\
\mathrm{mg} / \mathrm{ml}\end{array}$ & $\begin{array}{l}100 \\
\mu \mathrm{g} / \text { disk }\end{array}$ & $\begin{array}{l}200 \\
\mu \mathrm{g} / \text { disk }\end{array}$ & $\begin{array}{l}\mathrm{MIC} \\
\mathrm{mg} / \mathrm{ml}\end{array}$ & $\begin{array}{l}\mathrm{MBC} \\
\mathrm{mg} / \mathrm{ml}\end{array}$ \\
\hline \multicolumn{13}{|c|}{ Gram-positive bacteria } \\
\hline S. aureus & $16.67 \pm 0.58$ & $19 \pm 0$ & $1.56 \pm 0$ & $3.13 \pm 0$ & $13.67 \pm 0.58$ & $15.67 \pm 0.58$ & $0.25 \pm 0$ & $0.5 \pm 0$ & $15.67 \pm 0.58$ & $17.67 \pm 0.58$ & $0.25 \pm 0$ & $0.5 \pm 0$ \\
\hline MRSA & $16.67 \pm 0.58$ & $18.67 \pm 0.58$ & $1.56 \pm 0$ & $3.13 \pm 0$ & $13.33 \pm 0.58$ & $15.33 \pm 0.58$ & $0.25 \pm 0$ & $0.5 \pm 0$ & $15.67 \pm 0.58$ & $17.67 \pm 0.58$ & $0.25 \pm 0$ & $0.5 \pm 0$ \\
\hline \multicolumn{13}{|c|}{ Clinical MRSA } \\
\hline M 01 & $17 \pm 0$ & $20 \pm 0$ & $0.78 \pm 0$ & $1.56 \pm 0$ & $14 \pm 0$ & $16.33 \pm 0.58$ & $0.125 \pm 0$ & $0.25 \pm 0$ & $15.67 \pm 0.58$ & $18 \pm 0$ & $0.125 \pm 0$ & $0.25 \pm 0$ \\
\hline M 02 & $17.33 \pm 0.58$ & $19.33 \pm 0.58$ & $0.78 \pm 0$ & $1.56 \pm 0$ & $14.33 \pm 0.58$ & $16 \pm 0$ & $0.125 \pm 0$ & $0.25 \pm 0$ & $16 \pm 0$ & $17.67 \pm 0.58$ & $0.125 \pm 0$ & $0.25 \pm 0$ \\
\hline M 03 & $17.33 \pm 0.58$ & $19 \pm 0$ & $0.78 \pm 0$ & $1.56 \pm 0$ & $14.67 \pm 0.58$ & $16.33 \pm 0.58$ & $0.125 \pm 0$ & $0.25 \pm 0$ & $15.33 \pm 0.58$ & $17.33 \pm 0.58$ & $0.125 \pm 0$ & $0.25 \pm 0$ \\
\hline M 04 & $16.33 \pm 0.58$ & $19.67 \pm 0.58$ & $0.78 \pm 0$ & $1.56 \pm 0$ & $14.33 \pm 0.58$ & $16.33 \pm 0.58$ & $0.125 \pm 0$ & $0.25 \pm 0$ & $15.33 \pm 0.58$ & $17.33 \pm 0.58$ & $0.125 \pm 0$ & $0.25 \pm 0$ \\
\hline M 05 & $17 \pm 0$ & $20.33 \pm 0.58$ & $0.78 \pm 0$ & $1.56 \pm 0$ & $15 \pm 0$ & $17 \pm 0$ & $0.125 \pm 0$ & $0.25 \pm 0$ & $15.67 \pm 0.58$ & $18 \pm 0$ & $0.125 \pm 0$ & $0.25 \pm 0$ \\
\hline M 06 & $17.33 \pm 0.58$ & $20.33 \pm 0.58$ & $1.56 \pm 0$ & $3.13 \pm 0$ & $13.33 \pm 0.58$ & $15.33 \pm 0.58$ & $0.25 \pm 0$ & $0.5 \pm 0$ & $15.33 \pm 0.58$ & $17 \pm 0$ & $0.25 \pm 0$ & $0.5 \pm 0$ \\
\hline M 07 & $16.33 \pm 0.58$ & $18.33 \pm 0.58$ & $0.78 \pm 0$ & $1.56 \pm 0$ & $14 \pm 0$ & $17 \pm 0$ & $0.125 \pm 0$ & $0.25 \pm 0$ & $15.67 \pm 0.58$ & $17.67 \pm 0.58$ & $0.25 \pm 0$ & $0.5 \pm 0$ \\
\hline M 08 & $16.33 \pm 0.58$ & $19 \pm 0$ & $0.78 \pm 0$ & $1.56 \pm 0$ & $14 \pm 0$ & $16.67 \pm 0.58$ & $0.125 \pm 0$ & $0.25 \pm 0$ & $15.67 \pm 0.58$ & $17.67 \pm 0.58$ & $0.125 \pm 0$ & $0.25 \pm 0$ \\
\hline M 09 & $17 \pm 0$ & $19 \pm 0$ & $1.56 \pm 0$ & $3.13 \pm 0$ & $13.67 \pm 0.58$ & $16.33 \pm 0.58$ & $0.25 \pm 0$ & $0.5 \pm 0$ & $15 \pm 0$ & $17 \pm 0$ & $0.25 \pm 0$ & $0.5 \pm 0$ \\
\hline M 10 & $16.67 \pm 0.58$ & $19.33 \pm 0.58$ & $0.78 \pm 0$ & $1.56 \pm 0$ & $15.33 \pm 0.58$ & $17 \pm 0$ & $0.125 \pm 0$ & $0.25 \pm 0$ & $15.67 \pm 0.58$ & $17.67 \pm 0.58$ & $0.25 \pm 0$ & $0.5 \pm 0$ \\
\hline M 11 & $16 \pm 0.58$ & $18 \pm 0$ & $3.13 \pm 0$ & $6.25 \pm 0$ & $14.67 \pm 0.58$ & $16.67 \pm 0.58$ & $0.25 \pm 0$ & $0.5 \pm 0$ & $15.67 \pm 0.58$ & $17.33 \pm 0.58$ & $0.25 \pm 0$ & $0.5 \pm 0$ \\
\hline \multicolumn{13}{|c|}{ Gram-negative bacteria } \\
\hline P. aeruginos & $14.33 \pm 0.58$ & $19 \pm 0$ & $1.56 \pm 0$ & $3.13 \pm 0$ & $12.33 \pm 0.58$ & $14.33 \pm 0.58$ & $0.5 \pm 0$ & $1 \pm 0$ & $12.33 \pm 0.58$ & $14.33 \pm 0$ & $0.5 \pm 0$ & $1 \pm 0$ \\
\hline \multicolumn{13}{|c|}{ Clinical P.aeruginosa } \\
\hline P01 & $16.33 \pm 0.58$ & $20 \pm 0$ & $0.78 \pm 0$ & $1.56 \pm 0$ & $13 \pm 0$ & $15 \pm 0$ & $0.5 \pm 0$ & $1 \pm 0$ & $12.33 \pm 0.58$ & $15 \pm 0$ & $0.5 \pm 0$ & $1 \pm 0$ \\
\hline $\mathrm{P} 02$ & $14 \pm 0$ & $16.33 \pm 0.58$ & $3.13 \pm 0$ & $6.25 \pm 0$ & $10.67 \pm 0.58$ & $13 \pm 0$ & $1 \pm 0$ & $2 \pm 0$ & $10.67 \pm 0.58$ & $12 \pm 0$ & $1 \pm 0$ & $2 \pm 0$ \\
\hline $\mathrm{P} 03$ & $13.33 \pm 0.58$ & $15.33 \pm 0.58$ & $1.56 \pm 0$ & $3.13 \pm 0$ & $8.67 \pm 0.58$ & $15 \pm 0$ & $0.5 \pm 0$ & $1 \pm 0$ & $12.67 \pm 0.58$ & $14.67 \pm 0.58$ & $0.5 \pm 0$ & $1 \pm 0$ \\
\hline
\end{tabular}

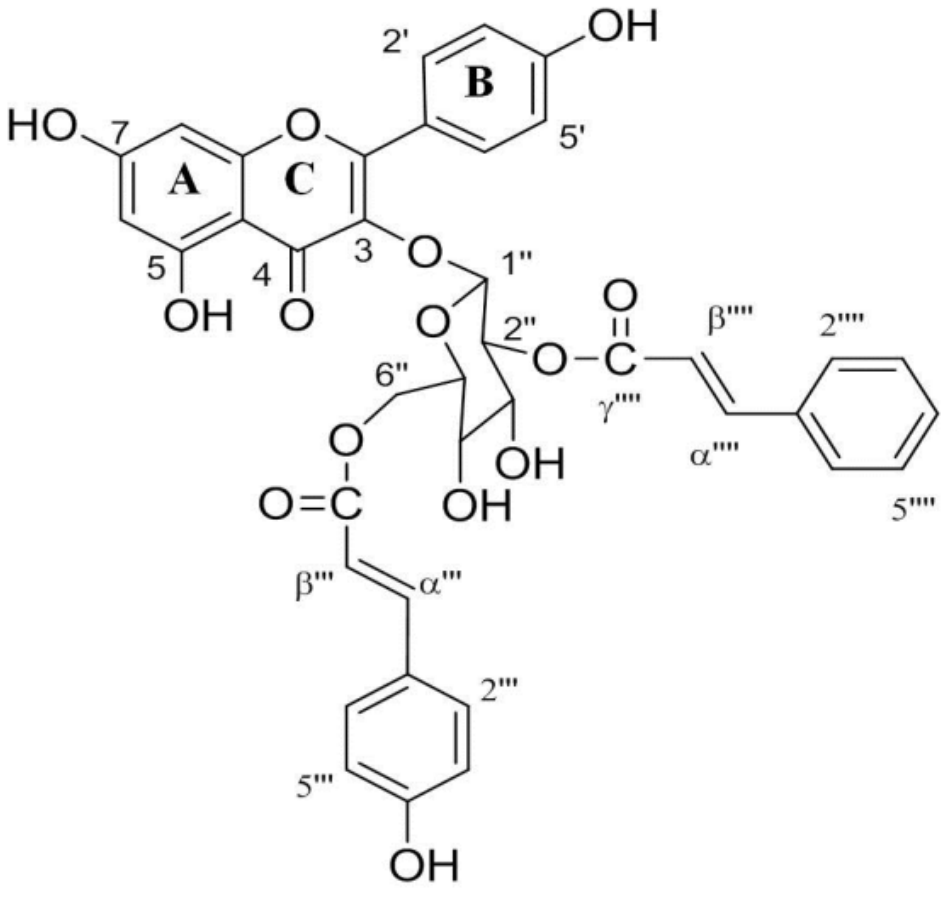

Fig. 1. Structure of Kaempferol-3-O-(2",6"-di-O-trans-p-coumaroyl)- $\beta$-D-glucopyranoside isolated from M. malabathricum Linn leaves extract 
Mourouge Saadi Alwash et al. / American Journal of Infectious Diseases 9 (2): 46-58, 2013

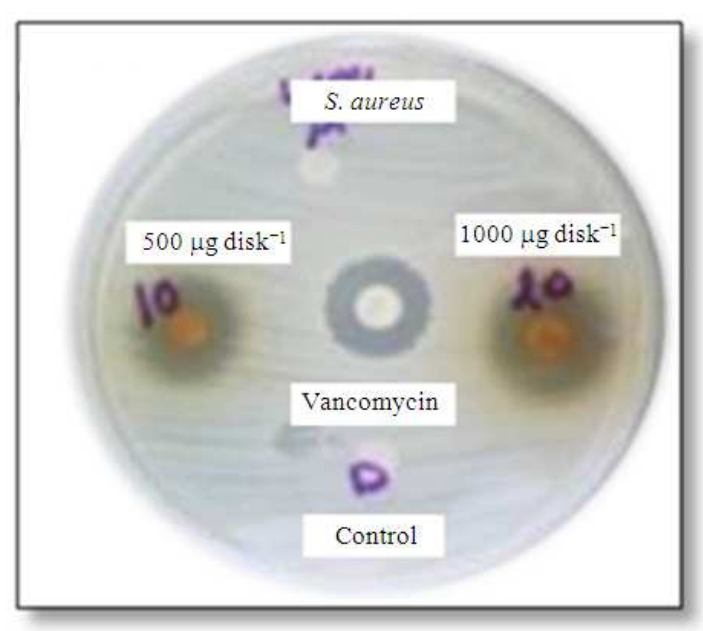

(A)

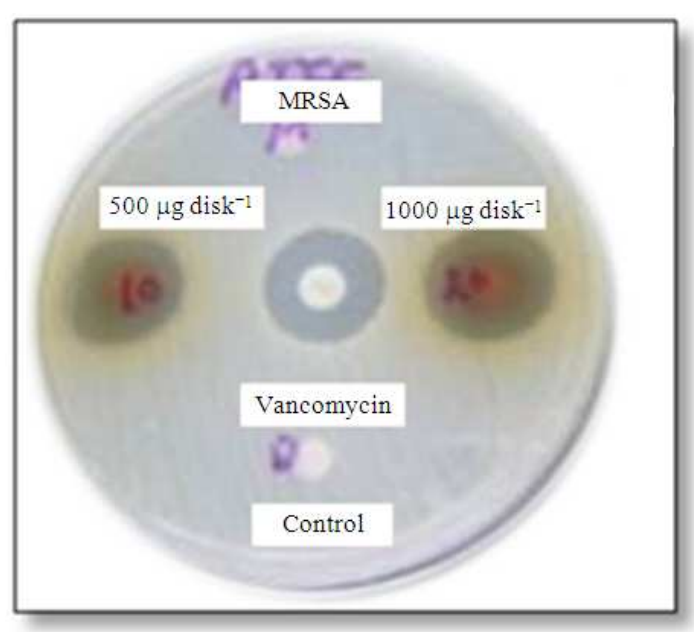

(B)

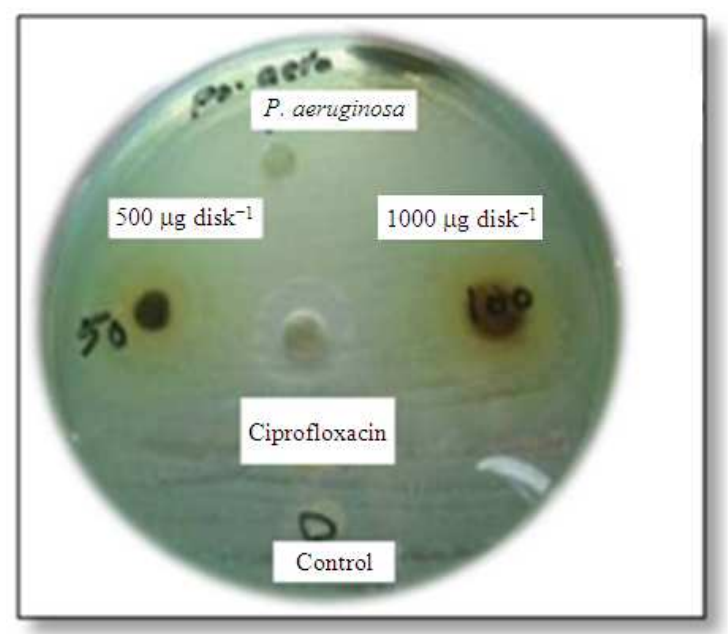

(C)

Fig. 2. (A): Zones of inhibition of S. aureus, (B): Zones of inhibition of methicillin resistant S. aureus and (C): Zones of inhibition of P. aeruginosa caused by the methanol extract of M. Malabathricum Leaves (MMML).

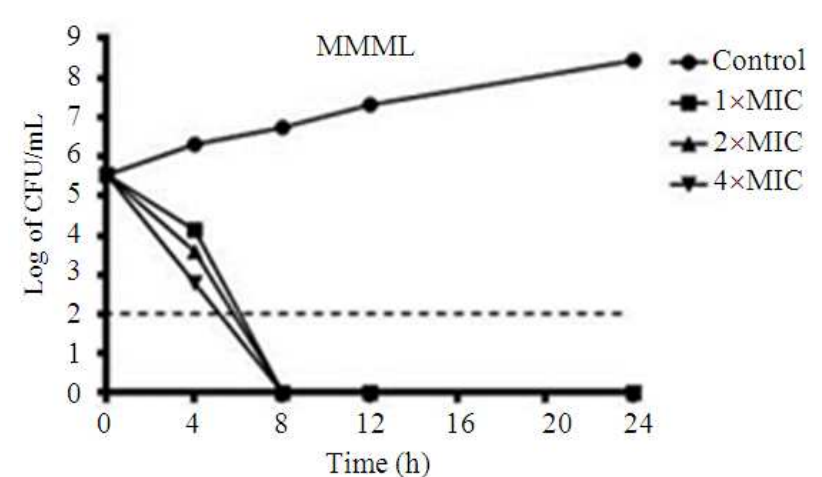

(A)

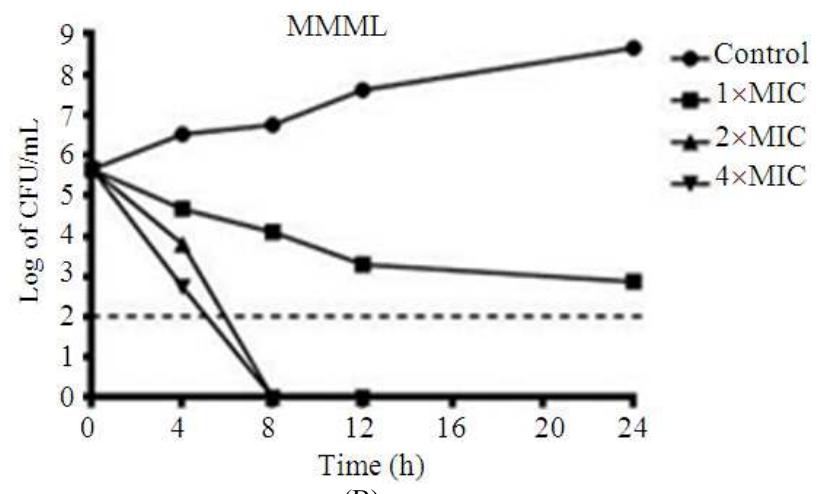

(B) 
Mourouge Saadi Alwash et al. / American Journal of Infectious Diseases 9 (2): 46-58, 2013
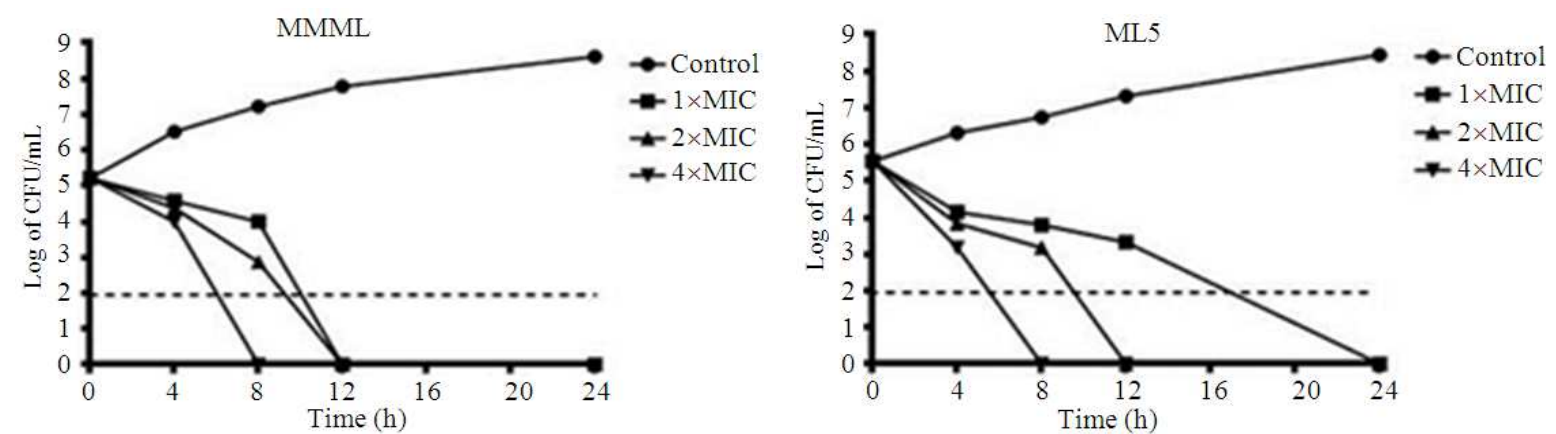

(C)

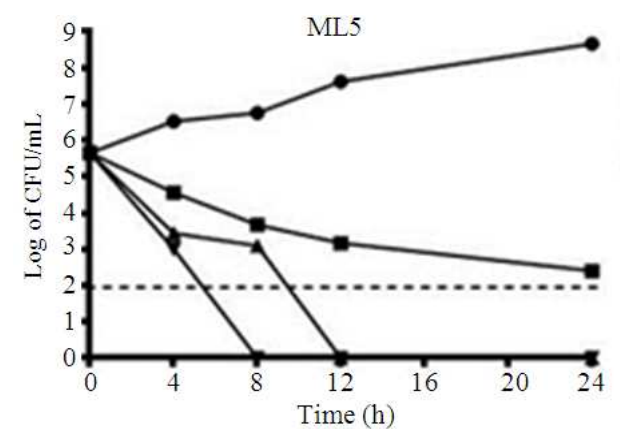

(E)

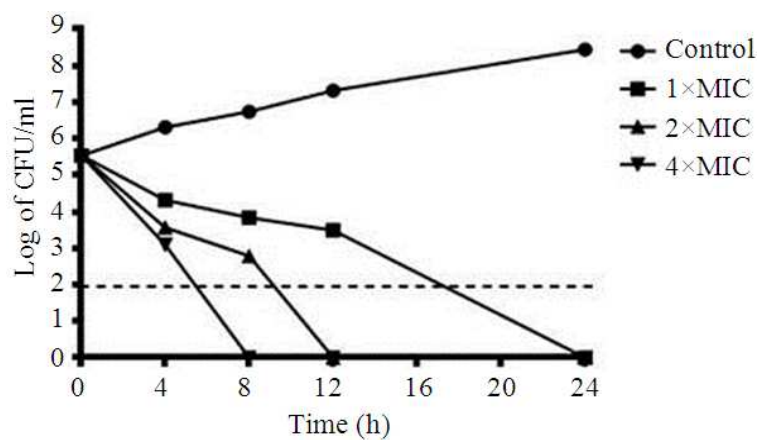

(G)

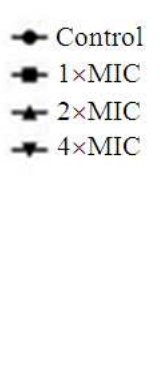

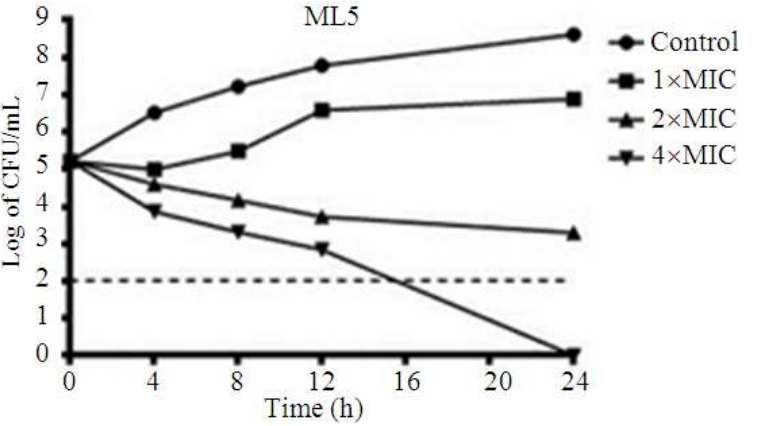

(F)

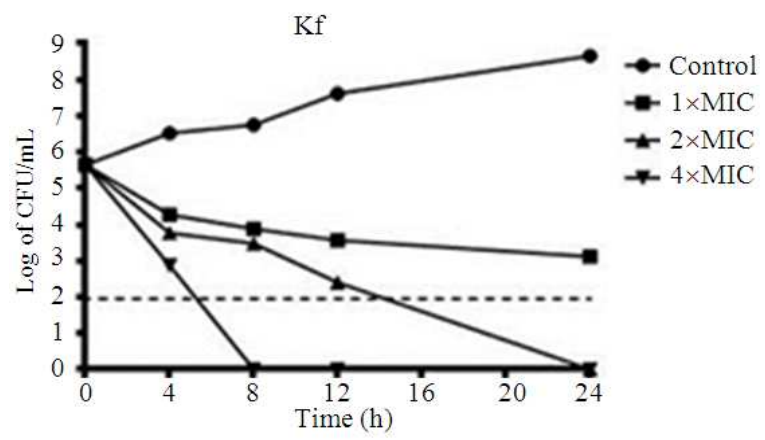

(H)

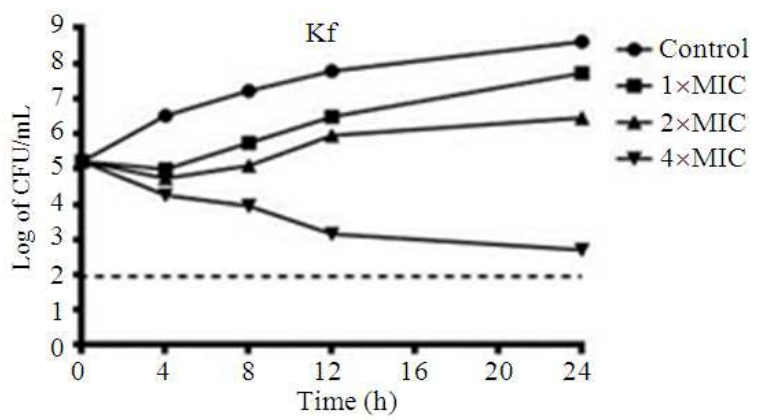

(I)

Fig. 3. Time-kill curves of Staphylococcus aureus (A-C), methicillin-resistant S. aureus (D-F) and Pseudomonas aeruginosa (G-I) after treatment with (1): The methanol extract of M. Malabathricum Leaves (MMML), (2): M. malabathricum leaves fraction (ML5) and (3): Kaempferol-3-O-(2",6"-di-O-trans- $p$-coumaroyl)- $\beta$-D-glucopyranoside (Kf) 

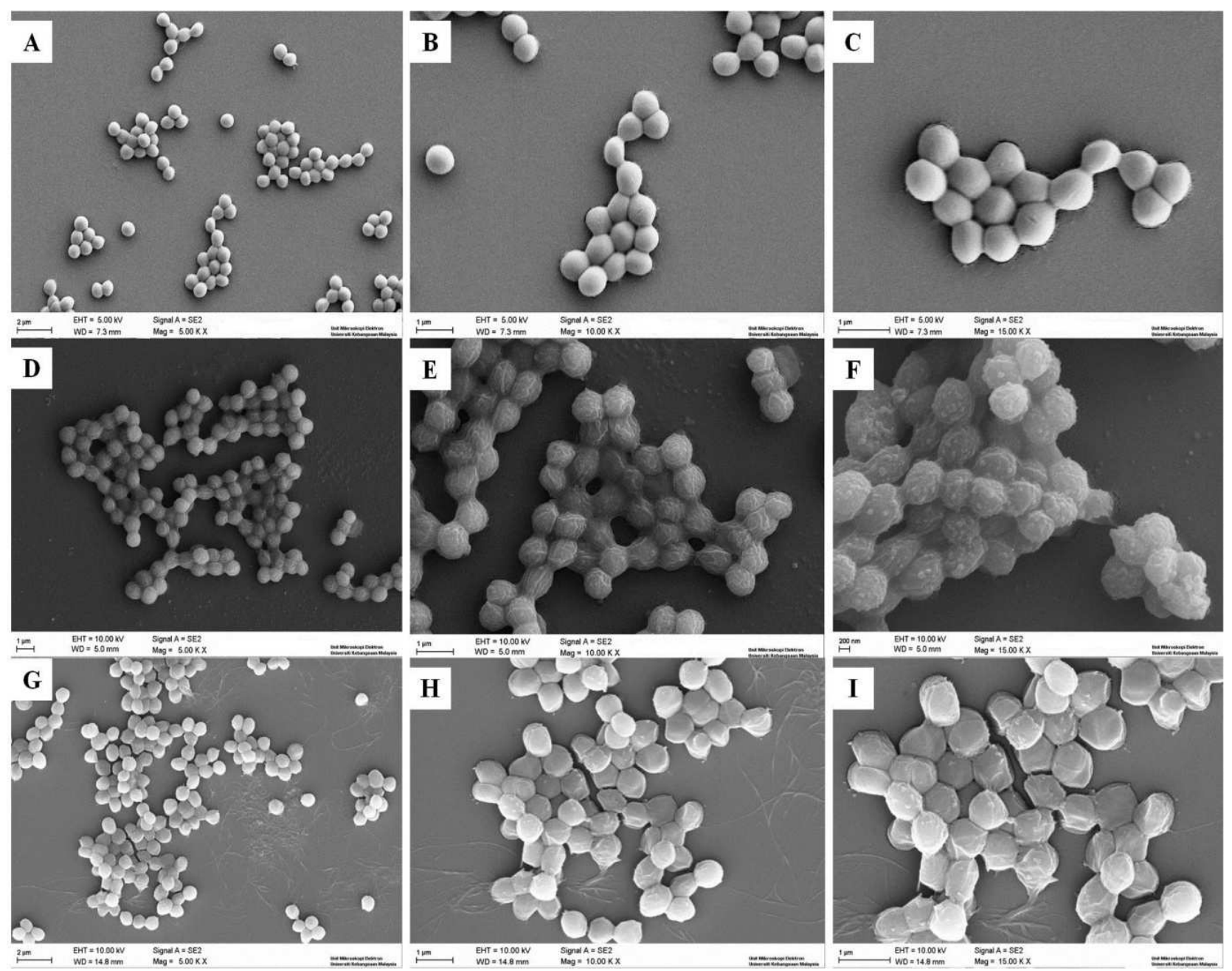

Fig. 4. External morphology of Staphylococcus aureus observed by Field Emission Scanning Electron Microscopy (FESEM). (A-C) untreated cells (control) incubated in Mueller-Hinton broth for $8 \mathrm{~h}$ at $37^{\circ} \mathrm{C}$,(D-F) treated cells incubated in Mueller-Hinton broth containing $0.5 \mathrm{mg} \mathrm{mL}^{-1}$ M. malabathricum leaves fraction (ML5) for $8 \mathrm{~h}$ at $37^{\circ} \mathrm{C}$ and (G-I) treated cells incubated in Mueller-Hinton broth containing $1.56 \mathrm{mg} \mathrm{mL}^{-1}$ the methanol extract of M. Malabathricum Leaves (MMML) for $6 \mathrm{~h}$ at $37^{\circ} \mathrm{C}$
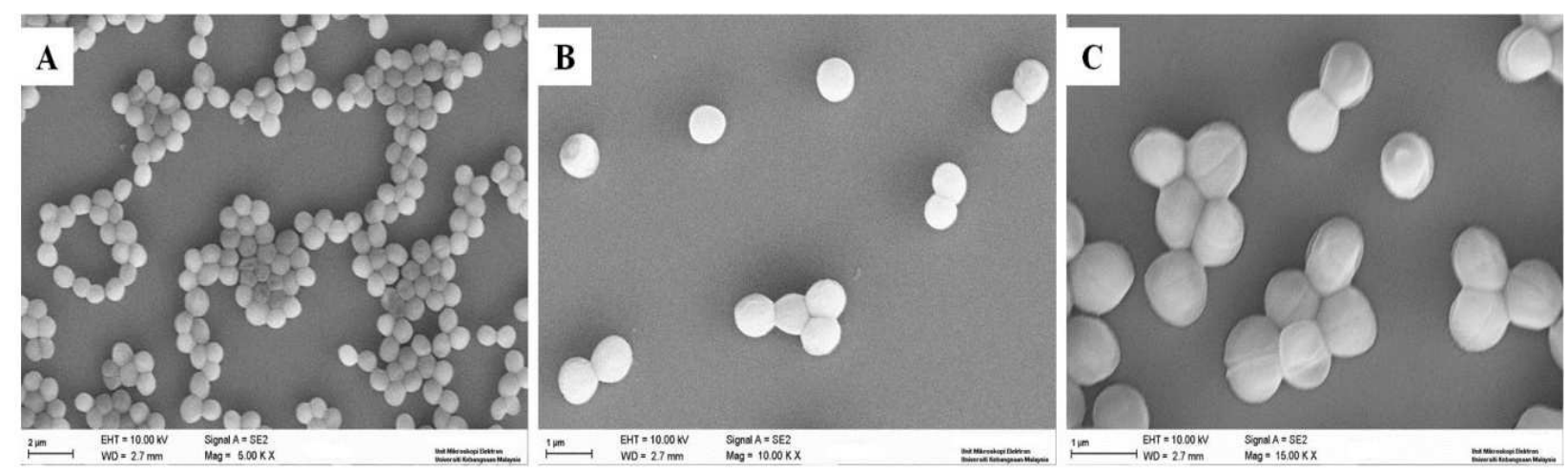
Mourouge Saadi Alwash et al. / American Journal of Infectious Diseases 9 (2): 46-58, 2013
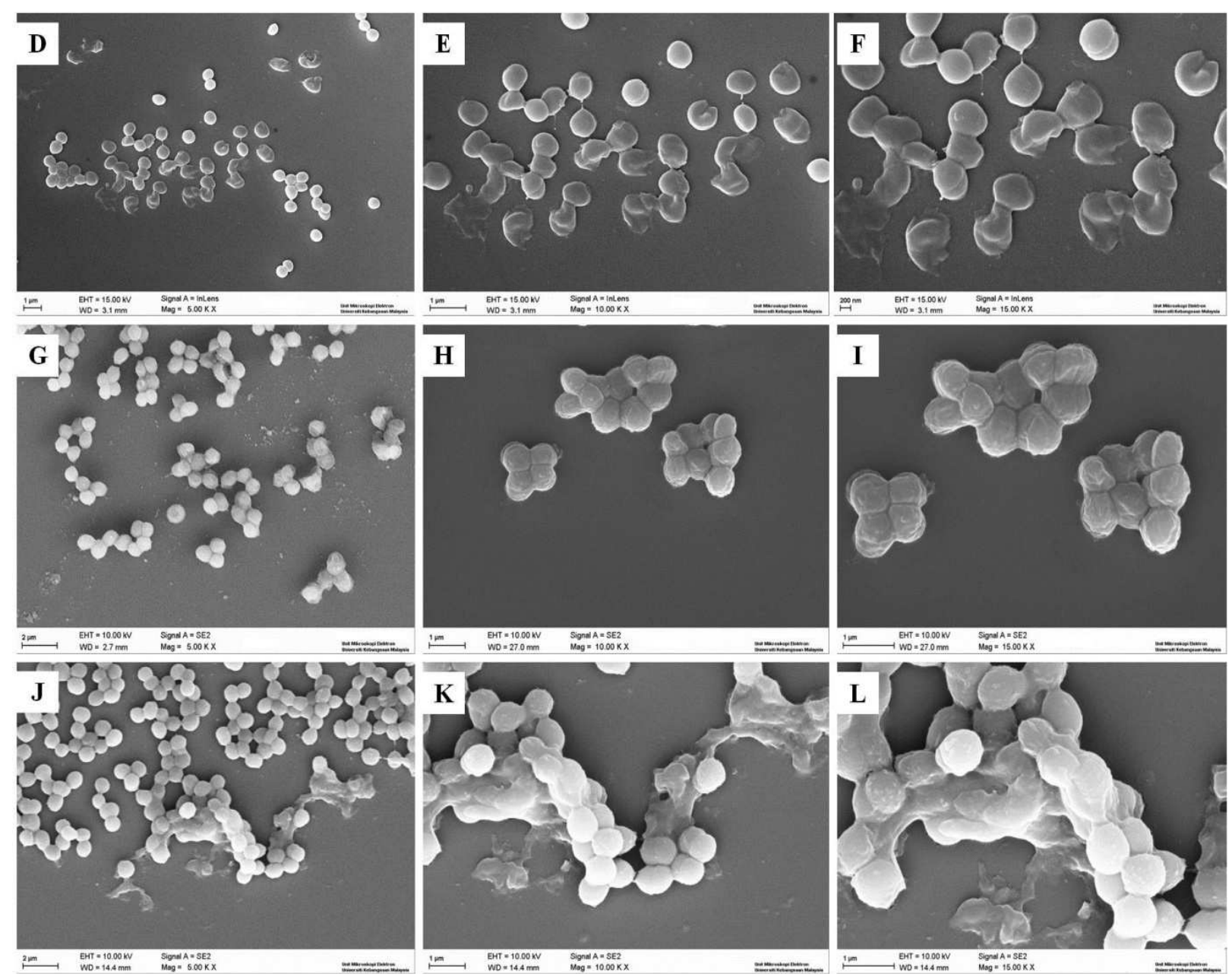

Fig. 5. External morphology of Methicillin-resistant Staphylococcus aureus observed by Field Emission Scanning Electron Microscopy (FESEM). (A-C) untreated cells (control) incubated in Mueller-Hinton broth for $8 \mathrm{~h}$ at $37^{\circ} \mathrm{C}$, (D-F) treated cells incubated in Mueller-Hinton broth containing $0.5 \mathrm{mg} \mathrm{mL} \mathrm{m}^{-1}$ Kaempferol-3-O-(2",6"-di-O-trans- $p$-coumaroyl)- $\beta$-Dglucopyranoside $(\mathrm{Kf})$ for $8 \mathrm{~h}$ at $37^{\circ} \mathrm{C}$, (G-I) treated cells incubated in Mueller-Hinton broth containing $0.5 \mathrm{mg} \mathrm{mL}^{-1} \mathrm{M}$. Malabathricum Leaves Fraction (ML5) for $8 \mathrm{~h}$ at $37^{\circ} \mathrm{C}$ and (J-L) treated cells incubated in Mueller-Hinton broth containing $1.56 \mathrm{mg} \mathrm{mL}^{-1}$ the methanol extract of M. Malabathricum Leaves (MMML) for $6 \mathrm{~h}$ at $37^{\circ} \mathrm{C}$
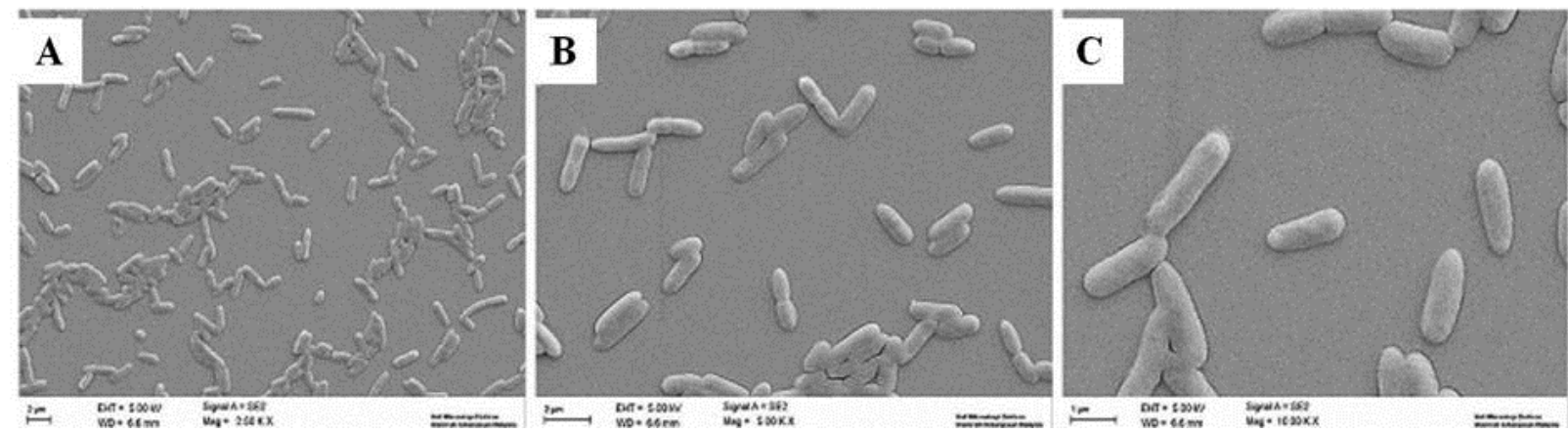

Science Publications 

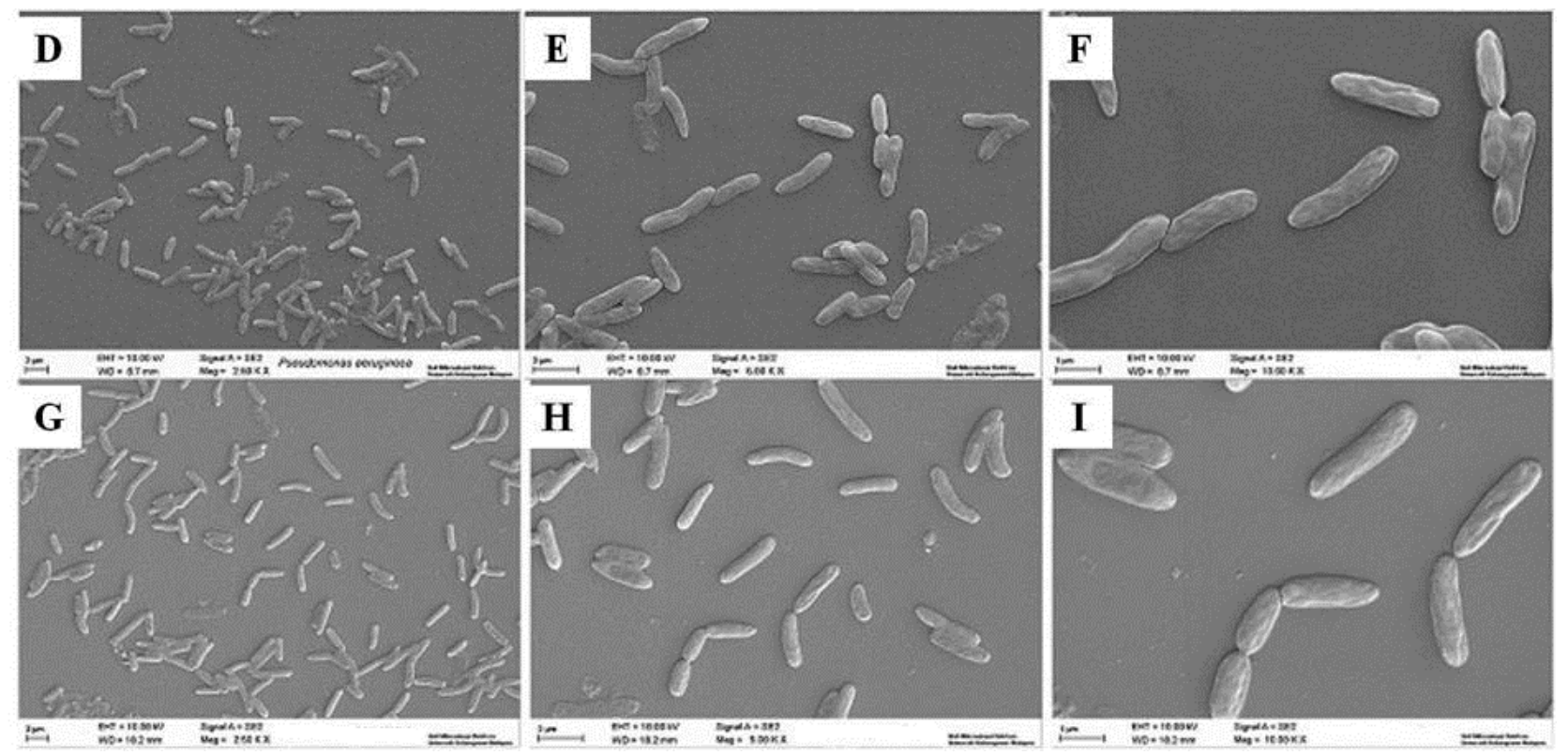

Fig. 6. External morphology of Pseudomonas aeruginosa observed by Field Emission Scanning Electron Microscopy (FESEM). (A-C) untreated cells (control) incubated in Mueller-Hinton broth for $8 \mathrm{~h}$ at $37^{\circ} \mathrm{C}$, (D-F) treated cells incubated in Mueller-Hinton broth containing $2 \mathrm{mg} \mathrm{mL}^{-1}$ M. malabathricum Leaves Fraction (ML5) for $8 \mathrm{~h}$ at $37^{\circ} \mathrm{C}$ and (G-I) treated cells incubated in MuellerHinton broth containing $1.56 \mathrm{mg} \mathrm{mL}$ the methanol extract of M. Malabathricum Leaves (MMML) for $8 \mathrm{~h}$ at $37^{\circ} \mathrm{C}$

Table 2. The MBC/MIC ratios of the methanol extract of M. malabathricum leaves (MMML), M. malabathricum leaves fraction (ML5) and Kaempferol-3-O-(2",6"-di-O-trans-p-coumaroyl)- $\beta$-D-glucopyranoside (Kf). No. of strains. 1: Staphylococcus aureus, 2-13: Methicillin-resistant $S$.aureus and 14-17: Pseudomonas aeruginosa

\begin{tabular}{|c|c|c|c|c|c|c|c|c|c|c|c|c|c|c|c|c|c|}
\hline \multirow{2}{*}{$\begin{array}{l}\text { Antibacterial } \\
\text { agents }\end{array}$} & \multicolumn{17}{|c|}{ No. of strains with MIC/MBC ratios } \\
\hline & 1 & 2 & 3 & 4 & 5 & 6 & 7 & 8 & 9 & 10 & 11 & 12 & 13 & 14 & 15 & 16 & 17 \\
\hline MMML & 2 & 2 & 2 & 2 & 2 & 2 & 2 & 2 & 2 & 2 & 2 & 2 & 2 & 2 & 2 & 2 & 2 \\
\hline ML5 & 2 & 2 & 2 & 2 & 2 & 2 & 2 & 2 & 2 & 2 & 2 & 2 & 2 & 2 & 2 & 2 & 2 \\
\hline $\mathrm{Kf}$ & 2 & 2 & 2 & 2 & 2 & 2 & 2 & 2 & 2 & 2 & 2 & 2 & 2 & 2 & 2 & 2 & 2 \\
\hline
\end{tabular}

The time-kill curves of ML5 against $S$. aureus, MRSA and $P$. aeruginosa are presented in Fig. 3D-F. The overall performance of ML5 was more effective against $S$. aureus and MRSA than $P$. aeruginosa. Complete inhibition of growth was achieved at concentrations $2 \times$ and $4 \times \mathrm{MIC}$ within 12 and $8 \mathrm{~h}$. Respectively for both $S$. aureus and MRSA, whereas the treatment of $P$. aeruginosa with ML5 at concentration $4 \times \mathrm{MIC}$ showed lethal effect on $P$. aeruginosa cells after $24 \mathrm{~h}$.

The data obtained from bioassay-guided fractionation (direct TLC-bioautography) revealed that the ML5 had the highest antibacterial activity in comparison with other fractions. Purification of the ML5 by Column Chromatography (CC) resulted in the isolation of $\mathrm{Kf}$. According to the time-kill curves of $\mathrm{Kf}$ against $S$. aureus, MRSA and $P$. aeruginosa, a gradual decline in the number of viable cells of $S$. aureus treated with $1 \times$ MIC after $24 \mathrm{~h}$ was observed, treatment with $\mathrm{Kf}$ achieved complete inhibition in growth when treated with $2 \times$ and $4 \times$ MIC after 12 and $8 \mathrm{~h}$ respectively (Fig. 3G). As shown in Fig. 3H, Kf exerted re-growth of MRSA at $1 \times$ MIC after 4h., while complete inhibition of growth occurred at concentrations $2 \times$ and $4 \times \mathrm{MIC}$ within 8 and $24 \mathrm{~h}$. respectively. It is worth to note that $\mathrm{Kf}$ was not effective against $P$. aeruginosa at all concentrations, consistent regrowth was observed after $8 \mathrm{~h}$ causing a loss of bactericidal activity (Fig. 3I).

\subsection{Field Emission Scanning Electron Microscopy (FESEM) study}

The effect of MMML, ML5 and Kf on the membrane morphology of $S$. aureus reference strain ATCC 11632, 
MRSA reference strain ATCC 43300 and P. aeruginosa reference strain ATCC 10145 was investigated using Field Emission Scanning Electron Microscopy (FESEM). Only Kf was chosen to be examined for its effect on MRSA by FESEM. Figure 4-6 showed the effect of MMML and ML5 on the membrane morphology of $S$. aureus, MRSA and P. aeruginosa. Untreated bacteria retained their morphology and showed a normal outer cell membrane. Following incubation with MMML and ML5 at concentration 1.56 and $0.5 \mathrm{mg} \mathrm{mL}^{-1}$ respectively, irregularities and physical damage were observed on the cell membrane (irregular shape and ruptured walls) of S. aureus, MRSA (Fig. 4 and 5). For MRSA treated with $0.5 \mathrm{mg} \mathrm{mL}^{-1} \mathrm{Kf}$, the membranes and shapes were dramatically disrupted (Fig. 5D-F). It should be noted that the treated bacteria were however, distinguishable from untreated bacteria.

FESEM images of $P$. aeruginosa (Fig. 6) showed that 1.56 and $2 \mathrm{mg} \mathrm{mL}^{-1}$ of MMML and ML5 respectively had little effect compared with $S$. aureus and MRSA. $P$. aeruginosa cells that incubated with MMML and ML5appear as distorted shapes and lost their integrity.

\section{DISCUSSION}

The problem of antibiotic-resistant organisms is established in both the healthcare setting and in community. Antibiotic-resistant organisms are capable of causing serious, life-threatening infections which are difficult to manage. These organisms are resistant to multiple classes of antimicrobial agents and therefore called multidrug-resistant organisms (Mulvey and Simor, 2009). Plants represent the most important source of antimicrobial compounds. Their usage in traditional medicine as remedies for several diseases is most popular for $80 \%$ of world population in Asia, Africa and South America (Gautam et al., 2012; Brusotti et al., 2013). The M. malabathricum leaves have been reported to possess antibacterial activity (Sunilson et al., 2008; Choudhury et al., 2011). Antibacterial activity of $M$. malabathricum was evaluated against standard and clinical isolates of Gram-positive and Gram-negative pathogenic bacteria by disk diffusion method and minimum inhibitory concentration (Table 1). Zakaria et al. (2011) reported that the methanolic extract of M. malabathricum possesses antimicrobial activity and this activity was ascribed to flavonoids. Flavonoids are the most known group of polyphenolic compounds for their pharmacological properties including antibacterial activity (Dulger and Hacioglu, 2009; Marzouk et al., 2010). A bio-guided study of ML5 resulted in isolation of Kaempferol-3-O-
(2",6"-di-O-trans-p-coumaroyl)- $\beta$-D-glucopyranoside. Teffo et al. (2010) reported that kaempferol and its glycosides are well known for their pharmacological activities including antibacterial activity. It is worth to note, the presence of 4 ' hydroxyl substitution in the $B$ ring, 5,7-dihydroxyl substitutions in the A ring and the substitution with 3-O-acyl chains in the $\mathrm{C}$ ring enhanced the anti-staphylococcal activity of flavonoids and that support the earlier findings of Otsuka et al. (2008).

S. aureus and MRSA to both ML5 and Kf were completely inhibited by $0.25 \pm 0 \mathrm{mg} \mathrm{mL} \mathrm{m}^{-1}$. The ratio of MBC to the MIC has been used to differentiate between the bactericidal and bacteriostatic activity. If the ratio $>$ 4 the antimicrobial agent is considered to be bactericidal while if it is more than $<4$, the antimicrobial agent is considered to have bacteriostatic properties (Forlenza et al., 1981). The ratio of MICs to the MBCs for MMML, ML5 and Kf of each of the 17 isolates was shown in Table 2. In this study the MBCs/MICs ratios of MMML, ML5 and Kf were $>4$, indicating that MMML, ML5 and Kf have a bactericidal activity rather than bacteriostatic activity.

The time-kill studies were used to assess the time needed by MMML, ML5 and Kf to act on bacterial cells viability of $S$. aureus, MRSA and $P$. aeruginosa. The MMML, ML5 showed bactericidal effects not only against $S$. aureus and tested MRSA but also against $P$. aeruginosa (Fig. 3A-F) whereas, the bioactive component $\mathrm{Kf}$ exerted bactericidal effect against $S$. aureus and tested MRSA and bacteriostatic effect against $P$. aeruginosa (Fig. 3G-I). In review of Bylka et al. (2004), it was stated that the antibacterial activity against Gram-negative bacteria including $P$. aeruginosa is higher with flavones, while flavonoid compounds having two or three hydroxyl groups in rings $\mathrm{A}$ or $\mathrm{B}$ were active against Gram-positive bacteria. Groups Data shown in Fig. 3 indicate that the bactericidal effect of MMML, ML5 and Kf on the viability of $S$. aureus, MRSA started before 4 h.and it takes longer time when a lower concentration is used.

The field emission scanning electron microscopy study of bacterial cells treated with MMML, ML5 and $\mathrm{Kf}$ revealed irregular bacterial surfaces and physical damage indicating that the MMML, ML5 and Kf disrupted the integrity of the membrane. Overall, the antibacterial activity of the tested samples was noticeable more effective against the Gram-positive bacteria compared to the Gram-negative bacteria. In fact, Gramnegative bacteria are typically more resistant to antimicrobial agents than Gram-positive bacteria and this 
occurrence has been explained by the presence of an outer-membrane permeability barrier, which limits access of the antimicrobial agents to their targets in the bacterial cell (Martins et al., 2013).

\section{CONCLUSION}

The MMML, ML5 and bioactive component Kf exerted potent inhibitory effects against all tested pathogenic bacteria. The $M$. malabathricum leaves fraction ML5 and Kaempferol-3-O-(2",6"-di-O-p-transcoumaroyl)- $\beta$-glucopyranoside exhibited statistic antibacterial activity against $S$. aureus strain and all tested MRSA. The MMML, ML5 exertedbactericidal effect against all tested bacteria. Field emission scanning electron microscopy showed that the MMML, ML5 and $\mathrm{Kf}$ disrupted the integrity of membrane. Therefore, the results obtained exhibited that MMML, ML5 and Kf have a potential alternative to antibiotics.

\section{ACKNOWLEDGMENT}

The study was supported by Research University Grant provided by Ministry of Education to Universiti Kebangsaan Malaysia (BKBP K006401 and DPP2013-022).

\section{REFERENCES}

Broekema, N.M., T.T. Van, T.A. Monson, S.A. Marshall and D.M. Warshauer, 2009. Comparison of cefoxitin and oxacillin disk diffusion methods fordetection of mecA-mediated resistance in Staphylococcus aureus in a large-scale study. J. Clin. Microbiol., 47: 217 219. DOI: $10.1128 /$ JCM.01506-08

Brusotti, G., I. Cesari, A. Dentamaro, G. Caccialanza and G. Massolini, 2013. Isolation and characterization of bioactive compounds from plant resources: The role of analysis in the ethnopharmacological approach. J. Pharmaceutical Biomed. Anal. DOI: 10.1016/J.JPBA.2013.03.007

Bylka, W., I. Matlawska and N.A. Pilewski, 2004. Natural flavonoids as antimicrobial agents. Jana, 7 : 24-31.

Chanda, S. and K. Rakholiya, 2011. Combination Therapy: Synergism between Natural Plant Extracts and Antibiotics Against Infectious Diseases. In: Science Against Microbial Pathogens: Communicating Current Research and Technological Advances, Mendez-Vilas, A. (Ed.), Formatex Research Center, Badajoz, ISBN-10: 8493984329, pp: 520-529.
Choudhury, M.D., D. Nath and A.D. Talukdar, 2011. Antimicrobial activity of Melastoma malabathricum L. Biol. Environ. Sci., 7: 76-78.

CLSI, 2006. Performance Standards for Antimicrobial Disk Susceptibility Tests. 9th Edn., Clinical and Laboratory Standards Institute, Wayne, Pa. USA.

Dulger, B. and N. Hacioglu, 2009. Antibacterial activity of three endemic hypericum species used in folkloric medicine against methicilin-resistant Staphylococcus aureus. Proceedings of the Anniversary Scientific Conference, (ASC' 09), Academic Education in Biology, pp: 763-765.

Forlenza, S.W., M.G. Newman, A.L. Horikoshi and U. Blachman, 1981. Antimicrobial susceptibility of capnocytophaga. Antimicrobial. Agents Chemotherapy, 19: 144-146. DOI: 10.1128/AAC.19.1.144

Gautam, M.K., M. Gangwar, G. Nath, C.V. Rao and R.K. Goel, 2012. In vitro antibacterial activity on human pathogens and total phenolic, flavonoid contents of Murraya paniculata Linn. leaves. Asian Pacific J. Trop. Biomed., 2: S1660-S1663. DOI: 10.1016/S2221-169(12)60472-9

Green, R.J., 2004. Antioxidant activity of peanut plant tissues. MSc Thesis, North Carolina State Univ. USA.

Mahomoodally, F., A. Mesaik, M.I. Choudhary, A.H. Subratty and A. Gurib-Fakim, 2012. In vitro modulation of oxidative burst via release of reactive oxygen species from immune cells by extracts of selected tropical medicinal herbs and food plants. Asian Pacific J. Tropical Med., 5: 440-447. DOI: 10.1016/S1995-7645(12)60075-3

Martins, S., E.L.C. Amorim, T.J.S.P. Sobrinho, A.M. Saraiva and M.N.C. Pisciottano et al., 2013. Antibacterial activity of crude methanolic extract and fractions obtained from Larrea tridentata leaves. Indus. Crops Products, 41: 306-311. DOI: 10.1016/j.indcrop.2012.04.037

Marzouk, B., Z. Marzouk, R. Decor, L. Mhadhebi and N. Fenina et al., 2010. Antibacterial and antifungal activities of several populations of Tunisian Citrullus colocynthis Schrad. Immature fruits and seeds. J. Mycol. Med., 20: 179-184. DOI: 10.1016/J.MYCMED.2010.05.006

Mulvey, M.R. and A.E. Simor, 2009. Antimicrobial resistance in hospitals: How concerned should we be? Canad. Med. Assoc., 180: 408-415. DOI: 10.1503/cmaj.080239 
NCCLS, 1999. Methods for Determining Bactericidal Activity of Antimicrobial Agents: Approved Guideline. 1st Edn., National Committee for Clinical Laboratory Standards, Wayne, ISBN-10: 1562383841, pp: 32 .

NCCLS, 2000. Methods for Dilution Antimicrobial Susceptibility Tests for Bacteria that Grow Aerobically: Approved Standard. 1st Edn., National Committee for Clinical Laboratory Standards, Wayne, $\mathrm{Pa}$, USA.

Nazlina, I., S. Norha, A.W. Zarina and I.B. Ahmad, 2008. Cytotoxicity and antiviral activity of Melastoma malabathricum extracts. Malaysian Applied Biol., 37: 53-55.

Otsuka, N., M.H. Liu, S. Shiota, W. Ogawa and T. Kuroda et al., 2008. Anti-Methicillin Resistant Staphylococcus Aureus (MRSA) compounds isolated from Laurus nobilis. Biol. Pharmaceutical Bull., 31: 1794-1797.

Rios, J.L. and M.C. Recio, 2005. Medicinal plants and antimicrobial activity. J. Ethnopharmacol., 100: 8084. DOI: $10.1016 /$ j.jep.2005.04.025

Sgariglia, M.A., J.R. Soberon, D.A. Sampietro, E.N. Quiroga and M.A. Vattuone, 2011. Isolation of antibacterial components from infusion of Caesalpinia paraguariensis bark. A bio-guided phytochemical study. Food Chem., 126: 395-404. DOI: 10.1016/j.foodchem.2010.10.104

Sharifa, A.A., Y.L. Neoh, M.I. Iswadi, O. Khairul and M. Abdul Halim et al., 2008. Effects of methanol, ethanol and aqueous extract of Plantago major on Gram positive bacteria, Gram negative bacteria and yeast. Ann. Microscopy, 8: 42-44.

Sharma, A., V.K. Patel, S. Rawat, P. Ramteke and R. Verma, 2010. Identification of the antibacterial component of some Indian medicinal plants against Klebsiella pneumonia. Int. J. Pharmacy Pharmaceutical Sci., 2: 123-127.

Sirat, H.M, D.M. Susanti, F. Ahmad, H. Takayama and M. Kitajima, 2010. Amides, triterpene and flavonoids from the leaves of Melastoma malabathricum L. J. Natural Med., 64: 492-495. DOI: $10.1007 / \mathrm{s} 11418-010-0431-8$
Sunilson, J., A.J. James, J. Thomas, P. Jayaraj and R. Varatharajan et al., 2008. Antibacterial and wound healing activities of Melastoma malabathricum Linn. Afr. J. Infect. Dis., 2: 68-73.

Teffo, L.S., M.A. Aderogba and J.N. Eloff, 2010. Antibacterial and antioxidant activities of four kaempferol methyl ethers isolated from Dodonaea viscose Jacq. var. angustifolia leaf extracts. South Afr. J. Botany, 76: 25-29. DOI: 10.1016/j.sajb.2009.06.010

Uhlemann, A.C., M. Otto, F.D. Lowy and F.R. DeLeo, 2013. Evolution of community and healthcareassociated methicillin-resistant Staphylococcus aureus. Infect. Genet. Evol. DOI: 10.1016/j.meegid.2013.04.030

WHO, 2012. Antimicrobial resistance. World Health Organization.

Zakaria, Z.A., R.N.S. RadenMohd. Nor, G. Hanan Kumar, Z.D.F. Abdul Ghani and M.R. Sulaiman et al., 2006. Antinociceptive, anti-inflammatory and antipyretic properties of Melastoma malabathricum leaves aqueous extract in experimental animals. Canad. J. Physiol. Pharmacol., 84: 1291-1299. DOI: 10.1139/Y06-083

Zakaria, Z.A., R.N.S. Raden Mohd Nor, G. Hanan Kumar, Z.D. Abdul Ghani and M.R. Sulaiman et al., 2011. Antinociceptive, anti-inflammatory and antipyretic properties of Melastoma malabathricum leaves aqueous extract in experimental animals. Canad. J. Physiol. Pharmacol., 84: 1291-1299. DOI: 10.1139/Y06-083

Zulaikah, M., I. Nazlina and I.B. Ahmad, 2008. Selective inhibition of genes in Methicillin Resistant Staphylococcus aureus (MRSA) treated with Melastoma malabathricum methanol extract. Sains Malaysiana, 37: 107-113. 